\title{
Eficiência de fungicidas no controle da podridão parda do pessegueiro e sua relação com parâmetros fisiológicos dos frutos
}

\section{Efficiency of fungicides in the control of brown rot in peaches and its relationship with physiological parameters of the fruits}

\author{
Elizandra Pivotto Pavanello ${ }^{1 *}$; Auri Brackmann ${ }^{2}$; Fabio Rodrigo Thewes ${ }^{3}$; \\ Vanderlei Both ${ }^{1}$; Jorge Roque Alves dos Santos ${ }^{4}$; Marcio Renan Weber Schorr ${ }^{1}$
}

\begin{abstract}
Resumo
A podridão parda, causada pelo fungo Monilinia fructicola, é a principal causa de perdas em pré e póscolheita em pêssegos. Objetivou-se avaliar a eficiência da aplicação pré-colheita de fungicidas sobre o controle da podridão parda a campo, após o armazenamento refrigerado e sua relação com parâmetros de maturação e qualidade dos frutos. Para tanto, foram avaliados os seguintes ingredientes ativos: [1] testemunha (aplicação de água); [2] captana; [3] iprodiona; [4] iminoctadina; [5] tebuconazol; [6] procimidona; [7] azoxistrobina; [8] difenoconazol; [9] azoxistrobina/difenoconazol; [10] trifloxistrobina/ tebuconazol; [11] sequência de iminoctadina + captana; [12] sequência de iminoctadina + iprodiona; [13] sequência de tebuconazol + captana; [14] sequência de tebuconazol + iprodiona. Todos os tratamentos foram aplicados nas doses recomendadas e obedecendo ao período de carência para a cultura. Os frutos foram avaliados na colheita, após o armazenamento a $-0,5^{\circ} \mathrm{C}$ por 40 dias, e durante seis dias a $20^{\circ} \mathrm{C}$. Até o momento da colheita, o fungicida que melhor controlou a podridão parda foi o difenoconazol. Após 40 dias de refrigeração $\left(-0,5^{\circ} \mathrm{C}\right)$ e mais seis dias exposição a $20^{\circ} \mathrm{C}$ o fungicida iminoctadina e a sua associação ao iprodiona apresentou bons resultados no controle da doença. A aplicação pré-colheita de captana causou escurecimento da epiderme dos frutos. O fungicida azoxistrobina influenciou na maturação dos frutos, diminuindo a acidez e a firmeza da polpa no momento da colheita. Bons níveis de controle da podridão parda do pessegueiro podem ser alcançados com a utilização dos produtos iminoctadina e iprodiona.
\end{abstract}

Palavras-chave: Monilinia fructicola, armazenamento refrigerado, escurecimento da epiderme

\begin{abstract}
The brown rot, caused by the fungus Monilinia fructicola, is the main cause for losses in pre and postharvest of peaches. The study aimed to evaluate the efficiency of preharvest application of fungicides on the control of brown rot in the field and during cold storage, and its relation to parameters of maturation and fruit quality. Therefore, we evaluated the following active ingredients: [1] control (water application), [2] captan; [3] iprodione; [4] iminoctadine; [5] tebuconazole; [6] procymidone; [7 ] azoxystrobin; [8] difenoconazole; [9] azoxystrobin / difenoconazole; [10] trifloxystrobin / tebuconazole; [11] sequence iminoctadine + captan; [12] sequence iminoctadine + iprodione; [13] sequence of tebuconazole + captan; [14] sequence of tebuconazole + iprodione. All treatments were applied according recommended doses and grace period for culture. The fruits were evaluated at harvest and after 40 days storage at $-0.5^{\circ} \mathrm{C}$,
\end{abstract}

1 Discentes do Curso de Doutorado em Agronomia. Dept ${ }^{\circ}$ de Fitotecnia, Universidade Federal de Santa Maria, UFSM. Santa Maria, RS. E-mail: elizandra_pavanello@yahoo.com.br; vanderleiboth@yahoo.com; marcioschorr@hotmail.com

2 Dr. em Agronomia, Prof. do Dept ${ }^{\circ}$ de Fitotecnia, UFSM, Santa Maria, RS. E-mail: auribrackmann@hotmail.com

3 Discente do Curso de Mestrado em Agronomia, Dept ${ }^{\circ}$ de Fitotecnia, UFSM, Santa Maria, RS. E-mail: fthewes@yahoo.com.br

${ }^{4}$ Eng $^{\text {o Agro }}{ }^{\circ}$, Agropecuária Schio Ltda., Vacaria, RS. E-mail: jorgeagromec@yahoo.com.br

* Autor para correspondência 
plus six days at $20^{\circ} \mathrm{C}$. At harvest time, the best control of brown rot was obtained with difenoconazole, while the fungicide iminoctadine and its association with iprodione showed good results in controlling brown rot after 40 days of cold storage, plus six days shelf life at $20^{\circ} \mathrm{C}$. The preharvest application of captan cause skin browning. The fungicide azoxystrobin influences the fruit maturation by decreasing acidity and firmness at harvest. Good levels of control of brown rot of peach can be achieved with the use of iminoctadine and iprodione.

Key words: Monilinia fructicola, cold storage, skin browning

A podridão parda, causada pelo fungo Monilinia fructicola, é uma das maiores preocupações dos produtores de pêssegos por causar elevadas perdas em pré e pós-colheita. As perdas pós-colheita normalmente ocorrem durante o transporte e o armazenamento (HONG et al., 1997) e são mais graves do que as de pré-colheita. Na Espanha, perdas pós-colheita atingem 59\% (LARENA et al., 2005), enquanto que no Brasil, as perdas podem variar entre 25\% (RASEIRA; QUEZADA, 2003) a 71,4\% (AMORIM et al., 2008), embora realizadas todas as medidas de profilaxia recomendadas.

Para o controle da podridão parda em pós-colheita é fundamental a eficiência das medidas adotadas na fase de pré-colheita, para reduzir o inóculo e evitar ao máximo a manifestação da doença durante o armazenamento e comercialização. O controle químico é o método mais adotado e eficiente, com pulverizações desde a floração à pré-colheita (MOREIRA; MAY DE MIO, 2009). A aplicação de fungicidas em pré-colheita é indispensável, principalmente para áreas com alta pressão de inóculo (LUO; MORGAN; MICHAILIDES, 2001) ou em casos de danos por insetos ou granizo na fase da frutificação. Devido a ineficiência de produtos, como o benomil, para o qual o fungo desenvolveu resistência, novos fungicidas foram desenvolvidos, como azoxistrobina e tebuconazol (MAY DE MIO et al., 2004), sendo cada vez maior a necessidade de encontrar produtos eficientes e manejo adequado da cultura para minimizar os riscos de resistência do patógeno. Diversos trabalhos dessa natureza já foram realizados, tanto com moléculas antigas (FORTES, 1994; MEDEIROS; MEDEIROS, 1997) como com moléculas recentes (MOREIRA; MAY DE MIO, 2009). No entanto, nesses trabalhos não foram avaliados o efeito fisiológico desses produtos durante a pós-colheita dos frutos.

O controle químico, até o momento, é o método mais eficiente para o controle da podridão parda, assim é essencial o acompanhamento da eficiência dos produtos utilizados pelos produtores. Desse modo, é importante garantir que os fungicidas protejam os frutos, possibilitando o seu armazenamento e comercialização, sem a necessidade da utilização de tratamentos específicos após a colheita. A aplicação de fungicidas nesse período aumenta os custos de produção, além de não ter produtos registrados para o controle da podridão parda, apenas o fungicida diclorana para o controle da podridão mole. Portanto, este trabalho teve por objetivo avaliar o efeito da aplicação pré-colheita de fungicidas sobre a incidência da podridão parda a campo e após o armazenamento refrigerado prolongado, bem como, investigar o seu efeito nas características de maturação e qualidade dos frutos.

O experimento a campo foi realizado em um pomar comercial de pessegueiro, no ano de 2010, no município de Santiago, Rio Grande do Sul, localizado numa altitude de $409 \mathrm{~m}$, na latitude $29^{\circ} 11^{\prime} 30^{\prime \prime}$ sul e longitude 54\%52'02" oeste. A cultivar utilizada foi 'Eldorado', de ciclo tardio, com plantas de oito anos de idade, espaçamento de 1,5 m entre plantas e $5 \mathrm{~m}$ entre linhas e sistema de condução em Y. O manejo fitossanitário iniciou com a eliminação dos frutos mumificados no período de repouso e seguiu com tratamentos químicos a partir da floração. Os produtos utilizados foram mancozebe (200 g $\left.100 \mathrm{~L}^{-1}\right)$ na plena florada e tebuconazol $\left(100 \mathrm{~mL} 100 \mathrm{~L}^{-1}\right)$ durante a queda das pétalas. No raleio foi realizada uma aplicação de mancozebe $\left(200{\left.\mathrm{~g} 100 \mathrm{~L}^{-1}\right)}^{-1}\right.$ tebuconazol (100 
$\left.\mathrm{mL} 100 \mathrm{~L}^{-1}\right)$. Após esse período, as aplicações précolheita foram realizadas conforme os tratamentos correspondentes ao experimento.

Os tratamentos constituíram-se da aplicação de nove fungicidas para o controle da podridão parda do pessegueiro, usados de forma isolada, mais quatro combinações entre alguns dos produtos mais utilizados pelos fruticultores do Rio Grande do Sul. Os tratamentos avaliados foram os seguintes ingredientes ativos: [1] testemunha (aplicação de água); [2] captana; [3] iprodiona; [4] iminoctadina; [5] tebuconazol; [6] procimidona; [7] azoxistrobina; [8] difenoconazol; [9] azoxistrobina/ difenoconazol; [10] trifloxistrobina/tebuconazol; [11] sequência de iminoctadina + captana; [12] sequência de iminoctadina + iprodiona; [13] sequência de tebuconazol + captana; [14] sequência de tebuconazol + iprodiona.

O delineamento experimental utilizado foi de blocos ao acaso, com quatro blocos e 14 tratamentos. Cada unidade experimental foi composta por quatro plantas, das quais duas foram utilizadas como bordadura. A aplicação dos tratamentos foi realizada a partir de 24 dias antes da colheita até o período de carência de cada produto, totalizando de duas a quatro aplicações, dependendo do produto. As aplicações foram realizadas com pulverizador costal (Jacto, bico cônico) de 20 L seguindo as doses recomendadas para cada ingrediente ativo e adequando-as para um volume de calda de $1000 \mathrm{~L}$ $\mathrm{ha}^{-1}$.

Após a colheita, uma amostra de 40 frutos por unidade experimental, totalizando 160 frutos por tratamento, sem infecção aparente, foi transportada para o laboratório. Os frutos foram classificados, descartando os que sofreram qualquer injúria decorrente da colheita e transporte. Após esse processo, 15 frutos de cada unidade experimental foram utilizados para as análises físico-químicas e de qualidade. Outros 25 frutos, de cada unidade experimental, foram acondicionados em redes de nylon para posterior armazenamento. O período de armazenamento foi de 40 dias à temperatura de $-0,5 \pm 0,2{ }^{\circ} \mathrm{C}$, com umidade relativa (UR) de $96 \pm 1 \%$. Cada tratamento foi acondicionado em uma caixa de plástico de $20 \mathrm{~kg}$. As avaliações foram realizadas na colheita, para observar o efeito dos fungicidas a campo, após os 40 dias de armazenamento refrigerado, e durante seis dias de exposição a $20 \pm 1$ ${ }^{\circ} \mathrm{C}$, com o objetivo de simular a vida de prateleira do produto.

Durante a fase de pré-colheita até o momento da colheita foi avaliada semanalmente a incidência de podridão parda no campo. A contagem foi realizada toda a semana, nos dias das aplicações dos fungicidas até o dia da colheita e os resultados foram expressos em porcentagem de podridão parda até o dia da colheita.

Após a colheita, uma amostra de cada tratamento com quatro repetições de 15 frutos foi analisada quanto aos seguintes parâmetros: a) Firmeza de polpa: determinada por meio de penetrômetro com ponteira de 7,9 mm, aplicado em dois lados opostos da região equatorial do fruto, onde foi retirada previamente a epiderme e expressa em Newton (N). b) Acidez titulável (AT): utilizou-se $10 \mathrm{~mL}$ de suco que foram diluídos em $100 \mathrm{~mL}$ de água destilada e titulados com uma solução de hidróxido de sódio 0,1 Normal até pH 8,1 sendo expressa em meq $100 \mathrm{~mL}^{-1}$. c) Sólidos solúveis (SS): determinação realizada com o refratômetro manual e a leitura corrigida em função do efeito da temperatura e expresso em ${ }^{\circ}$ Brix. d) Produção de etileno: obtida por cromatografia gasosa através de cromatógrafo marca Varian Star 3400X. Como fase estacionária foi usada uma coluna empacotada com Porapak $\mathrm{N}$ de 2,0 m de comprimento e tendo como fase móvel o nitrogênio. As temperaturas empregadas foram $90^{\circ} \mathrm{C}, 140^{\circ} \mathrm{C}$ e $200^{\circ} \mathrm{C}$ para coluna, injetor e detector, respectivamente. Uma amostra de 15 frutos foi acondicionada em recipientes de vidro com volume de $5 \mathrm{~L}$ hermeticamente vedados por aproximadamente uma hora. Em seguida, com auxílio de uma seringa, retirou-se duas amostras de $1 \mathrm{~mL}$ de gás contido em cada recipiente, 
sendo introduzida no injetor do equipamento. Os resultados da concentração de etileno foram obtidos em ppm e, considerando a massa dos frutos, o tempo de fechamento dos recipientes e o espaço livre do mesmo, foi possível calcular a produção de etileno, sendo expressa em $\mu \mathrm{L} \mathrm{C}_{2} \mathrm{H}_{4} \mathrm{~kg}^{-1} \mathrm{~h}^{-1}$. e) Taxa respiratória: determinada pela quantificação da produção de $\mathrm{CO}_{2}$. $\mathrm{O}$ ar dos mesmos recipientes utilizados para a determinação do etileno foi circulado através de um analisador de eletrônico de $\mathrm{CO}_{2}$, marca Schelle ${ }^{\circledR}$. A partir da concentração de $\mathrm{CO}_{2}$, do espaço livre dos recipientes, da massa dos frutos e do tempo de fechamento, foi calculada a respiração em $\mathrm{mL} \mathrm{CO}_{2} \mathrm{~kg}^{-1} \mathrm{~h}^{-1}$.

Para o armazenamento cada tratamento foi constituído de quatro repetições com 25 frutos e após o armazenamento refrigerado os frutos foram expostos à temperatura de $20{ }^{\circ} \mathrm{C}$ e os parâmetros avaliados foram: (i) Incidência de podridão parda; (ii) Porcentagem de frutos sadios; (iii) Incidência de outros fungos; (iv) Escurecimento da epiderme expresso por um índice, calculado pelo somatório da frequência de ocorrência, multiplicado pelo nível observado, resultado esse dividido pelo número total de frutos avaliados. Foi considerado nível $0=$ fruto sem escurecimento, nível $1=$ com menos de $10 \%$ da epiderme escurecida, nível $2=$ com $10-30 \%$ de escurecimento na epiderme e nível $3=$ com mais de $30 \%$ de escurecimento.

Os experimentos foram conduzidos segundo o delineamento blocos ao acaso até o momento da colheita e após o armazenamento em blocos ao acaso com parcelas subdivididas no tempo. Os dados, antes da análise de variância (ANOVA), foram submetidos ao teste de normalidade dos erros, pelo teste de Lilliefors e os parâmetros que não apresentavam normalidade dos erros foram transformados pela fórmula $\operatorname{arc} . \operatorname{sen} \sqrt{\mathrm{x} / 100}$ para serem submetidos com os demais à análise de variância. As médias foram comparadas pelo teste Scott-knott em nível de 5\% de probabilidade de erro.

Até o momento da colheita, o fungicida que melhor controlou a podridão parda foi o difenoconazol, apresentando $0,84 \%$ de incidência de podridões causadas pelo fungo $M$. fructicola, enquanto que a testemunha apresentou 10,2\% (Figura 1). Os fungicidas tebuconazol, procimidona, azoxistrobina e o fungicida composto por trifloxistrobina/tebuconazol não diferiram entre si e com incidência de podridão parda entre $(2,7 \%$ e $4 \%)$. Em estudos comparando a diferença entre o efeito dos tratamentos curativos e protetores, Holb e Schnabel (2007) verificaram que os triazóis apresentam uma alta atividade protetora, sendo mais eficientes para o controle da podridão parda. Além do eficiente controle pelos fungicidas do grupo dos triazóis (difenoconazol e tebuconazol), os fungicidas do grupo das estrobilurinas (azoxistrobina e trifloxistrobina) também apresentaram controle sobre a doença, A azoxistrobina atua preventivamente, inibindo a germinação de esporos e os estágios iniciais do desenvolvimento dos fungos, possuindo ação curativa e erradicante, atuando também nos estágios de pós-germinação de um grande número de fungos, além de conferir ação antiesporulante (BARTLETT et al., 2002). 
Figura 1. Incidência de Monilinia fructicola, sólidos solúveis, acidez titulável, firmeza de polpa, produção de etileno e taxa respiratória após a colheita, em pêssegos cv. Eldorado, tratados com fungicidas em pré-colheita.

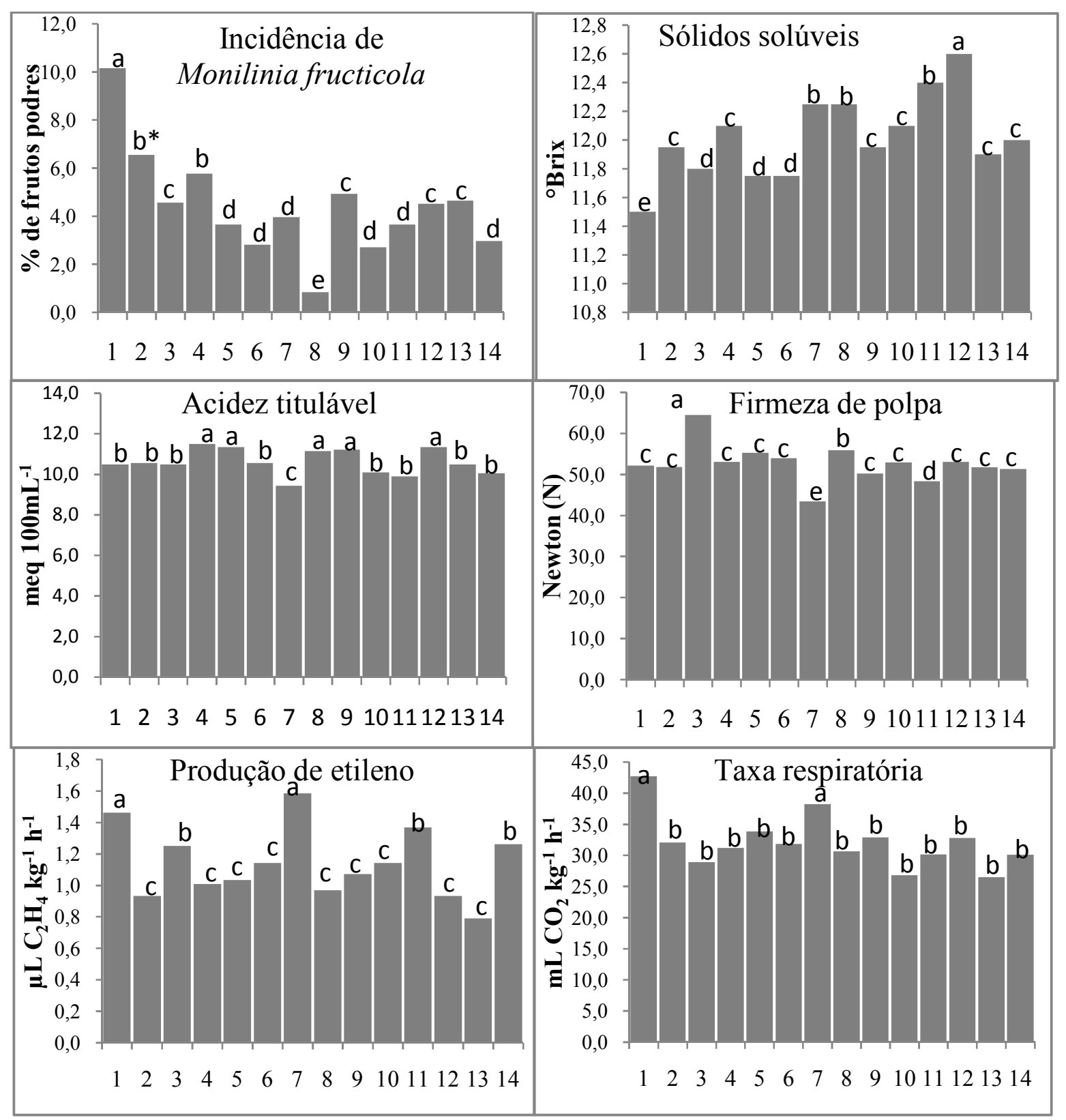

Tratamentos: [1] testemunha (aplicação de água); [2] captana (4x**); [3] iprodiona (4x); [4] iminoctadina (2x); [5] tebuconazol (3x); [6] procimidona (3x); [7] azoxistrobina (3x); [8] difenoconazol (3x); [9] azoxistrobina/difenoconazol (3x); [10] trifloxistrobina/ tebuconazol $* * *(3 \mathrm{x})$; [11] sequência de iminoctadina $(2 \mathrm{x})+$ captana $(2 \mathrm{x}) * * * * ;$ [12] sequência de iminoctadina $(2 \mathrm{x})+$ iprodiona $(2 \mathrm{x})$; [13] sequência de tebuconazol $(2 \mathrm{x})+$ captana $(2 \mathrm{x})$; [14] sequência de tebuconazol $(2 \mathrm{x})+$ iprodiona $(2 \mathrm{x}) . *$ Tratamentos com médias não seguidas pela mesma letra diferem pelo teste de Scott knott a 5\% de probabilidade de erro. ** Número de aplicações. *** Produto comercial contendo dois ingredientes ativo. **** Duas aplicações do primeiro i.a. e duas do segundo i.a.

Fonte: Elaboração dos autores. 
$\mathrm{Na}$ avaliação do teor de $\mathrm{SS}$, o tratamento que apresentou maior concentração foi a sequência dos fungicidas iminoctadina + iprodiona (12,6 ${ }^{\circ}$ Brix), enquanto que a testemunha apresentou os menores teores, ambos diferindo estatisticamente dos demais tratamentos (Figura 1). Resultado diferente foi encontrado para a cv. BR-1, em que o fungicida iminoctadina tris albesillate não afetou esse parâmetro (MOREIRA; MAY DE MIO, 2009). A AT foi maior nos frutos tratados com o iminoctadina, tebuconazol, difenoconazol, azoxistrobina/difenoconazol e no tratamento envolvendo a sequência dos fungicidas iminoctadina + iprodiona, enquanto que o menor valor foi encontrado nos frutos tratados com o fungicida azoxistrobina. Os demais tratamentos não diferiram da testemunha (Figura 1). Seguindo a mesma tendência, o parâmetro firmeza de polpa foi menor nos frutos tratados com azoxistrobina, enquanto que o maior valor foi observado nos frutos tratados com iprodiona (Figura 1). Provavelmente, os baixos valores de SS, promovidos pelos fungicidas difenoconazol, iprodiona, iminoctadina e tebuconazol, e a alta firmeza de polpa, promovida pelo difenoconazol e o iprodiona, desempenharam papel importante na eficiência do controle da podridão parda, com provável aumento na resistência do fruto à infecção fúngica.

Com exceção da azoxistrobina, todos os demais fungicidas testados contribuíram para uma menor produção de etileno e taxa respiratória dos frutos (Figura 1). Provavelmente os fungicidas apresentam efeito sobre a maturação dos frutos. Pesquisas mostram que alguns compostos têm efeito positivo sobre a fisiologia das plantas, inibindo a síntese de etileno em tecidos de brotos de trigo, resultando em atraso na senescência foliar e uma prolongada atividade fotossintética (TÖFOLI, 2002). Nos frutos foi observado um efeito semelhante, uma vez que, com exceção daqueles tratados com o fungicida azoxistrobina, todos os demais tiveram o metabolismo retardado quando comparado à testemunha, evidenciado pela menor produção de etileno e respiração. Os frutos tratados com azoxistrobina tiveram comportamento semelhante à testemunha quanto à produção de etileno e respiração, o que justifica os menores valores de acidez e firmeza de polpa dos mesmos, em função do maior metabolismo, apesar de mostrar uma eficiência intermediária para o controle de podridões.

Após os 40 dias de armazenamento refrigerado, durante todos os dias avaliados, os frutos da testemunha apresentaram a maior incidência de podridão parda, diferindo estatisticamente dos demais tratamentos, com valores superiores a $70 \%$ a partir do $4^{\circ}$ dia de exposição a $20^{\circ} \mathrm{C}$, com exceção para dois dias, em que não diferiu do fungicida captana (Tabela 1). O tratamento com melhor desempenho para o controle do fungo $M$. fructicola foi a sucessão dos fungicidas iminoctadina + iprodiona, em que a incidência fúngica foi de $2 \%$ aos dois dias e $4 \%$ aos quatro e seis dias de avaliação, não havendo evolução na incidência de podridão ao longo das avaliações (Tabela 1). A utilização do iminoctadina de forma isolada também apresentou bons resultados no controle da podridão parda (Tabela 1). Estes resultados reforçam os encontrados por Moreira e May-De Mio (2009), em que o iminoctadina controlou em $96 \%$ da incidência do fungo $M$. fructicola após seis dias a $5{ }^{\circ} \mathrm{C}$ mais cinco dias a $25{ }^{\circ} \mathrm{C}$. O fungicida iminoctadina, pertencente ao grupo químico guanidina e de ação multisítio, passa a ser uma importante alternativa para o controle da doença. A sua associação a outros grupos, como os triazois (tebuconazol) e os dicarboximida (iprodione), é uma eficiente estratégia de manejo. Dessa forma, o controle da podridão parda torna-se eficiente, sem a necessidade de tratamentos químicos em póscolheita. Além disso, a rotação de diferentes grupos químicos desempenha papel importante em retardar o aparecimento de resistência para os triazois (BURNETT; LALANCETTE; MCFARLAND, 2010). Atribui-se o alto nível de controle à alta fungitoxicidade destes produtos (AZEVEDO, 2003) e, provavelmente, ao curto intervalo entre as aplicações (sete dias), a eficiência na aplicação e à baixa ocorrência de chuvas no período pré-colheita. 
Tabela 1. Incidência de podridão parda, incidência de Rhizopus, porcentagem de frutos sadios e escurecimento da epiderme de pêssegos cv. Eldorado, tratados com fungicidas em pré-colheita e armazenados a $-0,5{ }^{\circ} \mathrm{C}$ por 40 dias, mais seis dias a $20^{\circ} \mathrm{C}$. Santa Maria, 2011.

\begin{tabular}{|c|c|c|c|c|}
\hline \multirow{3}{*}{ Tratamentos } & \multicolumn{3}{|c|}{ Podridão parda (\%) } & \multirow[t]{2}{*}{ Rizhopus sp. (\%) } \\
\hline & \multicolumn{3}{|c|}{ Dias a $20^{\circ} \mathrm{C}$} & \\
\hline & 2 dias & 4 dias & 6 dias & 6 dias \\
\hline Testemunha & $12,6 \mathrm{Ca} *$ & $70,2 \mathrm{Ba}$ & $93,7 \mathrm{Aa}$ & $12,6 \mathrm{~d}$ \\
\hline Captana $\left(4 x^{* *}\right)$ & $13,0 \mathrm{Ca}$ & $43,3 \mathrm{Bb}$ & $52,5 \mathrm{Ab}$ & $26,8 b$ \\
\hline Iprodiona $(4 \mathrm{x})$ & $6,72 \mathrm{Cb}$ & $21,9 \mathrm{Bd}$ & 33,9Ad & $10,1 d$ \\
\hline Iminoctadina $(2 \mathrm{x})$ & $5,02 \mathrm{Bb}$ & 9,77Af & $11,9 \mathrm{Ag}$ & $24,6 b$ \\
\hline Tebuconazol (3x) & $1,04 \mathrm{Bc}$ & $18,2 \mathrm{Ae}$ & $20,6 \mathrm{Ae}$ & $39,5 \mathrm{a}$ \\
\hline Procimidona $(3 \mathrm{x})$ & $3,00 \mathrm{Bc}$ & $17,3 \mathrm{Ae}$ & $20,5 \mathrm{Ae}$ & $18,3 \mathrm{c}$ \\
\hline Azoxistrobina $(3 \mathrm{x})$ & $7,44 \mathrm{Cb}$ & $32,6 \mathrm{Bc}$ & 41,9Ac & $17,2 \mathrm{c}$ \\
\hline Difenoconazol (3x) & $8,09 \mathrm{Bb}$ & $15,4 \mathrm{Ae}$ & $16,2 \mathrm{Af}$ & $21,5 \mathrm{c}$ \\
\hline Azoxist./Difenoc. $(3 \mathrm{x})^{* * *}$ & $6,39 \mathrm{Cb}$ & $22,7 \mathrm{Bd}$ & $30,2 \mathrm{Ad}$ & $17,3 \mathrm{c}$ \\
\hline Triflox./Tebuc. $(3 \mathrm{x})^{* * *}$ & $0,00 \mathrm{Cd}$ & $11,3 \mathrm{Bf}$ & $17,6 \mathrm{Af}$ & $11,3 d$ \\
\hline Iminoctad. $(2 \mathrm{x})+$ Capt. $(2 \mathrm{x})^{* * * *}$ & $5,75 \mathrm{Cb}$ & $11,8 \mathrm{Bf}$ & $19,3 \mathrm{Af}$ & $31,7 \mathrm{a}$ \\
\hline Iminoctad. $(2 \mathrm{x})+$ Iprod. $(2 \mathrm{x})^{* * * *}$ & $2,00 \mathrm{Ac}$ & $4,00 \mathrm{Ag}$ & $4,0 \mathrm{Ah}$ & $20,0 \mathrm{c}$ \\
\hline Tebuc. $(2 \mathrm{x})+$ Capt. $(2 \mathrm{x})^{* * * *}$ & $5,22 \mathrm{Cb}$ & $16,6 \mathrm{Be}$ & 26,9Ad & $17,6 \mathrm{c}$ \\
\hline Tebuc. $(2 \mathrm{x})+$ Iprod. $(2 \mathrm{x})^{* * * *}$ & $7,36 \mathrm{Cb}$ & $15,8 \mathrm{Be}$ & $24,3 \mathrm{Ae}$ & $33,2 \mathrm{a}$ \\
\hline CV $(\%)$ & & 10,4 & & 11,7 \\
\hline \multirow{3}{*}{ Tratamentos } & \multicolumn{3}{|c|}{ Escurecimento da epiderme (índice 0-3) } & Frutos sadios (\%) \\
\hline & \multicolumn{4}{|c|}{ Dias a $20^{\circ} \mathrm{C}$} \\
\hline & $\mathbf{0}$ dias & 2 dias & 4 dias & 6 dias \\
\hline Testemunha & $0,18 \mathrm{Ba}^{*}$ & $0,19 \mathrm{Bb}$ & $0,23 \mathrm{Ab}$ & $4,09 \mathrm{e}$ \\
\hline Captana $\left(4 x^{* *}\right)$ & $0,19 \mathrm{Ba}$ & $0,25 \mathrm{Aa}$ & $0,27 \mathrm{Aa}$ & $27,8 \mathrm{~d}$ \\
\hline Iprodiona (4x) & $0,15 \mathrm{Ab}$ & $0,17 \mathrm{Ac}$ & $0,18 \mathrm{Ac}$ & $46,0 \mathrm{~b}$ \\
\hline Iminoctadina $(2 x)$ & $0,08 \mathrm{Bc}$ & $0,09 \mathrm{Be}$ & $0,15 \mathrm{Ad}$ & $44,7 b$ \\
\hline Tebuconazol (3x) & $0,02 \mathrm{Ad}$ & $0,02 \mathrm{Af}$ & $0,02 \mathrm{Af}$ & $36,0 \mathrm{c}$ \\
\hline Procimidona $(3 \mathrm{x})$ & $0,07 \mathrm{Ac}$ & $0,07 \mathrm{Ae}$ & $0,08 \mathrm{Ae}$ & $52,8 \mathrm{a}$ \\
\hline Azoxistrobina $(3 \mathrm{x})$ & $0,10 \mathrm{Bc}$ & $0,10 \mathrm{Be}$ & $0,14 \mathrm{Ad}$ & $28,2 d$ \\
\hline Difenoconazol (3x) & $0,08 \mathrm{Bc}$ & $0,08 \mathrm{Be}$ & $0,17 \mathrm{Ad}$ & $47,0 \mathrm{~b}$ \\
\hline Azoxist./Difenoc. $(3 \mathrm{x})^{* * *}$ & $0,04 \mathrm{Cd}$ & $0,06 \mathrm{Be}$ & $0,14 \mathrm{Ad}$ & $35,9 \mathrm{c}$ \\
\hline Triflox./Tebuc. $(3 \mathrm{x})^{* * *}$ & $0,02 \mathrm{Bd}$ & $0,02 \mathrm{Bf}$ & $0,12 \mathrm{Ad}$ & $53,4 \mathrm{a}$ \\
\hline Iminoctad. $(2 \mathrm{x})+$ Capt. $(2 \mathrm{x})^{* * * *}$ & $0,06 \mathrm{Cc}$ & $0,14 \mathrm{Bd}$ & $0,27 \mathrm{Aa}$ & $48,2 b$ \\
\hline Iminoctad. $(2 \mathrm{x})+$ Iprod. $(2 \mathrm{x})^{* * * *}$ & $0,04 \mathrm{Cd}$ & $0,07 \mathrm{Be}$ & $0,12 \mathrm{Ad}$ & $57,0 \mathrm{a}$ \\
\hline Tebuc. $(2 \mathrm{x})+$ Capt. $(2 \mathrm{x})^{* * * *}$ & $0,04 \mathrm{Cd}$ & $0,14 \mathrm{Bd}$ & $0,29 \mathrm{Aa}$ & $55,4 \mathrm{a}$ \\
\hline Tebuc. $(2 \mathrm{x})+$ Iprod. $(2 \mathrm{x})^{* * * *}$ & $0,01 \mathrm{Bd}$ & $0,02 \mathrm{Bf}$ & $0,08 \mathrm{Ae}$ & $40,5 \mathrm{c}$ \\
\hline CV $(\%)$ & & 27,2 & & 5,48 \\
\hline
\end{tabular}

* Tratamentos com médias não seguidas pela mesma letra minúscula na vertical (fungicidas) e maiúscula na horizontal (datas de avaliação), diferem pelo teste de Scott knott a 5\% de probabilidade de erro.

** Número de aplicações.

*** Produto comercial contendo dois ingredientes ativo.

**** Duas aplicações do primeiro i.a. e duas do segundo i.a.

Fonte: Elaboração dos autores. 
Embora o tratamento envolvendo a sequência dos fungicidas iminoctadina + iprodiona tenha sido eficiente para o controle da podridão parda apresentou aos seis dias a $20^{\circ} \mathrm{C}$ apenas $57 \%$ de frutos sadios, sendo que somente $4 \%$ de podridões foram causadas por Monilinia fructicola. Isso se deve à ação de outros fungos pós-colheita, como o caso do Rhizopus sp., manifestando-se em 20\% dos frutos desse tratamento (Tabela1). Essa alta incidência de podridões por Rhizopus stolonifer aos 40 dias de armazenamento, mais seis dias de exposição a $20^{\circ} \mathrm{C}$, provavelmente está relacionada ao prolongado período de armazenamento à baixa temperatura, causando danos na epiderme do fruto, o que predispõe à maior infecção por patógenos de origem pós-colheita. Além disso, é provável que o avançado estádio de maturação dos frutos, após 40 dias de armazenamento, tenha afetado a estrutura da parede celular, resultando em mudanças na textura do fruto, favorecendo a infecção. Entre os fungicidas testados, a menor incidência de Rhizopus stolonifer foi observada nos tratamentos com iprodiona e trifloxistrobina/tebuconazol, com no máximo de 11,3\% (Tabela 1). A alta incidência de Rhizopus em relação à aplicação de determinados fungicidas, provavelmente, está relacionada à seletividade dos produtos. No caso do iprodiona, é um fungicida com ação sobre uma ampla gama de patógenos e alta eficiência preventiva, garantindo, por isso, bons níveis de controle para fungos causadores de podridões, podendo ser aplicado inclusive em pós-colheita (EHR; KEMMITT, 2002). Quanto à incidência de escurecimento da epiderme, todos os tratamentos envolvendo a aplicação de captana apresentaram maior índice de escurecimento, causando danos à epiderme dos frutos e depreciando a sua qualidade. Ao contrário, no tratamento com a aplicação isolada de tebuconazol, a incidência de escurecimento foi próxima a zero (Tabela 1). Esses resultados estão de acordo com os encontrados por Giehl et al. (2006), ao avaliar 15 fungicidas para o controle da podridão parda
O fungicida difenoconazol apresenta a maior eficiência para o controle da podridão parda durante a fase de pré-colheita, enquanto os produtos tebuconazol, procimidona, azoxistrobina e trifloxistrobina/tebuconazol têm eficiência intermediária. A aplicação pré-colheita da sucessão dos fungicidas iminoctadina + iprodiona é a mais eficiente para o controle pós-colheita da podridão parda, porém não é eficiente no controle de Rhizopus stolonifer durante a pós-colheita.

A aplicação de fungicidas afeta a maturação dos frutos, com exceção do fungicida azoxistrobina, enquanto o fungicida captana aplicado em précolheita interfere de forma negativa na qualidade dos frutos após o armazenamento, causando escurecimento da epiderme.

\section{Referências}

AMORIM, L.; MARTINS, M. C.; LOURENÇO, S. A.; GUTIERREZ, A. S. D.; ABREU, F. M.; GONÇALVES, F. P. Stone fruit injuries and damage at the wholesale market of São Paulo, Brazil. Postharvest Biology and Technology, Amsterdam, v. 47, n. 3, p. 353-357, 2008.

AZEVEDO, L. A. S. Fungicidas protetores: fundamentos para uso racional. Campinas: Emopi Edit. e Graf., 2003. $320 \mathrm{p}$.

BARTLETT, D. W.; CLOUGH, J. M.; GODWIN, J. R.; HALL, A. A.; HAMER, M.; PARR-DOBRZANSKI, B. Review: the strobilurin fungicides. Pest Manage, London, v. 58, n. 7, p. 649-662, 2002.

BURNETT, A.; LALANCETTE, N.; MCFARLAND, K. First report of the peach brown rot fungus Monilinia fructicola resistant to demethylation inhibitor fungicides in New Jersey. Plant Disease, Saint Paul, v. 94, n. 1, p. 126-126, 2010.

EHR, R. J.; KEMMITT, G. Periodic table of the fungicides. Indianapolis: Dow Agrosciences, v. 1, 2002.

FORTES, J. F. Controle de Monilinia fructicola em Prunus persica na pré-colheita. Fitopatologia Brasileira, Brasília, v. 19, p. 327-327, 1994. Suplemento.

GIEHL, R. F. H.; PINTO, J. A. V.; EISERMANN, A. C.; BORDIGNON, B. C. S.; WEBER, A.; BRACKMANN, A. Aplicação pré-colheita de fungicidas para o controle de podridão parda (Monilinia fructicola) em pêssegos 
'Eldorado'. In: ENCONTRO NACIONAL DE FRUTICULTURA DE CLIMA TEMPERADO, 9., 2006, Fraiburgo. Anais... Fraiburgo: EPAGRI, 2006. p. 62.

HOLB, I. J.; SCHNABEL, G. Differential effect of triazoles on mycelial growth and disease measurements of Monilinia fructicola isolates with reduced sensitivity to DMI fungicides. Crop Protection, Guildford, v. 26, n. 5, p. $753-759,2007$.

HONG, C.; HOLTZ, B. A.; MORGAN, D. P.; MICHAILIDES, T. J. Significance of thinned fruit as a source of the secondary inoculum of Monilinia fructicola in California nectarine orchards. Plant Disease, Saint Paul, v. 81, n. 5, p. 519-524, 1997.

LARENA, I.; TORRES, R.; DE CAL; A.; LIÑÁN, M.; MELGAREJO, P.; DOMENICHINI, P.; BELLINI A.; MANDRIN, J. F.; LICHOU, J.; OCHOA DE ERIBE, X.; USALL, J. Biological control of postharvest brown rot (Monilinia spp.) of peaches by field applications of Epicoccum nigrum. Biological Control, San Diego, v. 32, n. 2, p. 305-310, 2005.

LUO, Y.; MORGAN, D. P.; MICHAILIDES, T. J. Risk analysis of brown rot blossom blight of prune caused by Monilinia fructicola. Phytopathology, Saint Paul, v. 91, n. 8, p. 759-768, 2001.
MAY DE MIO, L. L; MONTEIRO, L. B.; NAZARENO, N. R. X. de; HICKEL, E. Classificação e manejo dos agroquímicos em fruteiras de caroço. In: MONTEIRO, L. B.; MAY-DE MIO, L. L.; SERRAT, B. M.; MEDEIROS, G.; MEDEIROS, C. A. Fruteiras de caroço: uma visão ecológica. Curitiba: UFPR, 2004. p. 263-297.

MEDEIROS, G.; MEDEIROS, C.A. Controle químico de Monilinia fructicola em pessegueiro. Fitopatologia Brasileira, Brasília, v. 22, p. 283-283, 1997. Suplemento.

MOREIRA, L. M.; MAY-DE MIO, L. M. Controle da podridão parda do pessegueiro com fungicidas e fosfitos avaliados em pré e pós-colheita. Ciência e Agrotecnologia, Lavras, v. 33, n. 2, p. 405-411, 2009.

RASEIRA, M. C. B.; QUEZADA, A. C. Pêssego produção. Embrapa Clima Temperado: Pelotas, Brasília: EMBRAPA, 2003. 162 p. (Informações Tecnológicas, frutas do Brasil, 49).

TÖFOLI, J. G. Ação de fungicidas e acibensolars-methyl no controle da pinta preta do tomateiro. 2002. Dissertação (Mestrado em Agronomia) - Universidade Estadual Paulista Julio de Mesquita Filho. Faculdade Ciências Agronômicas, Botucatu. 
